\title{
Posterior cortical atrophy - a prototypical case of dementia beginning with visual symptoms: case report
}

\author{
Atrofia cortical posterior - um caso prototípico de demência iniciando com sintomas visuais: relato de caso
}

Leonardo Ferreira Caixeta ${ }^{1}$, Alexandre Chater Taleb², Bruno Galafassi Ghinl², Vânia lúcia Dias Soares ${ }^{3}$, Victor de Melo Caixeta ${ }^{4}$, Ciro Vargas ${ }^{4}$

\begin{abstract}
Dementia presenting with prominent higher order visual symptoms may be observed in a range of neurodegenerative conditions and is often challenging to diagnose. We describe a case of progressive dementia presenting with prominent visual cortical symptoms. A 55-year-old, right-handed, woman with early onset of visual impairment not associated with anterior visual pathology, presenting with dyslexia, visual agnosia, Balint's syndrome, and spatial disorientation. Ophthalmologists should consider this condition especially in presenile patients with slowly progressive higher-order visual symptoms. Although described in association with different conditions, it may also occur in Alzheimer disease.
\end{abstract}

Keywords: Brain/pathology; Mental disorders/complications; Dementia/complications; Alzheimer disease/complications; Vision disorders/etiology; Case report

\section{RESUMO}

As demências que se apresentam predominantemente com sintomas visuais associativos podem ser observadas em diferentes condições neurodegenerativas, sendo seu diagnóstico muitas vezes desafiador. Descrevemos um caso com demência progressiva que se apresentam com sintomas visuais proeminentes. Mulher de 55 anos, destra, com início precoce de déficits visuais não associados a patologia visual anterior, apresentando dislexia, agnosia visual, sindrome de Balint e desorientação espacial. Os oftalmologistas devem ter em mente essa condição especialmente em pacientes pré-senis com queixas visuais complexas elentamente progressivas. Apesar de descritas em diferentes condições, pode ocorrer na doença de Alzheimer.

Descritores: Encéfalo/patologia; Transtornos mentais/complicações; Demência/ complicações; Doença de Alzheimer/complicações; Transtornos da visão/etiologia; Relato de caso

\section{INTRODUCTION}

Posterior cortical atrophy (PCA) or progressive posterior cortical dysfunction syndrome (PPCD) is a rare but disabling dementia syndrome described for the first time by Benson et al. in 1988 (1). This progressive dementia initially presents with visual disturbances and is characterized by visuospatial and visual perceptual impairment, visual agnosia, including some or all features of Balint's syndrome and Gerstmann's syndrome, with a later onset of cognitive decline generally associated with typical Alzheimer's disease ${ }^{(1-4)}$. PCA is assumed as a clinical syndrome in which Alzheimer's disease seems to be the major (but not exclusively) pathologic cause $\mathrm{e}^{(1-4)}$, being also described in associations with Huntingtons' disease ${ }^{(5)}$, Lewy body dementia, Creutzfeldt-Jakob disease and cortico-basal degeneration ${ }^{(3)}$. Visual hallucinations occur in up to $25 \%$ of patients who are diagnosed with posterior cortical atrophy ${ }^{(1,4)}$.

We report a typical case of a patient with posterior cortical atrophy who presented initially with ophthalmologic complains in order to present this rare dementia subtype as a relevant differential diagnosis to other primarily ophthalmologic complains.

\section{CASE REPORT}

A 55-year-old, right-handed, 11 years of schooling, married businesswoman with a three-year history, characterized by early onset of visual impairment not associated with anterior visual pathology, was brought to the ophthalmologic department by her husband for visual disturbances characterized by visuospatial and visual perceptual impairment. The husband complained that patient could not read perfectly anymore because of the "difficulty following the lines of text while reading." Besides that, the patient could not see what was in front of her and, when reaching for objects (such as door handle or sink tap), she missed them, and relied more on her touch than on eye sight. Two years after disease onset, she began progressive spatial disorientation, affecting her ability to drive a car. Family members noticed that she had begun having difficulty in performing home tasks one year ago. She needed help in instrumental activities of daily living, for instance, she was unable to use the phone, because she did not see the handset cradle and the numbers, she was unable to light the oven, she had difficulty climbing stairs. Throughout the course of the disease, she became confused with right and left hands, the symptoms deteriorated and she had to be aided in basic activities of daily living, presented word-finding difficulties and worsened decision-making. She was treated with cholinesterase inhibitor (donepezil $10 \mathrm{mg}$ daily) associated with memantine (20 mg daily), but responded very poorly. No family history of dementia was reported.

On examination, she scored 22 out of 30 points on the MMSE. She had difficulty in performing manual tasks under visual guidance bilaterally (optic ataxia), jerky intrusions when attempting to perform
Submitted for publication: June 20, 2013

Accepted for publication: September 29, 2013

Study carried out at Universidade Federal de Goiás, UFG - Goiânia, GO, Brazil.

Physician,Faculdade de Medicina, Universidade Federal de Goiás, UFG - Goiânia (GO), Brazil.

Physician, Department of Nuclear Medicine, Centro de Diagnóstico por Imagem - Goiânia (GO), Physician, Department of Nuclear Medicine, Centro de Diagnostico por Imagem - Goiânia (GO), Brazil.

Physician, Cognitive Psychiatry Unit, Hospital das Clínicas, Universidade Federal de Goiás, UFG Goiânia (GO), Brazil.

Physician, Health Sciences Postgraduate Program, Universidade Federal de Goiás, UFG - Goiânia (GO), Brazil.
Funding: No specific financial support was available for this study.

Disclosure of potential conflicts of interest: L.Caixeta, None; A.C.Taleb, None; B.G.Ghini, None; V.L.D.Soares, None; V.M.Caixeta, None; C.Vargas, None.

Correspondence address: Leonardo Caixeta. Avenida Cristo Rei, 626 - Setor Jaó - Goiânia (GO) 74674-290 - Brazil - E-mail: leonardocaixeta1@gmail.com 
smooth pursuit eye movements (ocular apraxia) and could not see two objects at the same time (for instance, two pencils of different colors on the table) (simultanagnosia). When the examiner showed some dark line drawings pointing at one for her to name, she could only see the examiner's fingernail. She had difficulties in performing commands that required right and left orientation. There were normal optic fundi, brisk symmetric tendon reflexes and no frontal releasing signs. On subsequent examinations, the visual signs and language functions, especially naming and fluency, reading and writing, deteriorated. She presented bilateral finger agnosia, and acalculia. She presented a severe difficulty on confrontation field examination, because most of the time she could not see the target (simultanagnosia, ocular apraxia). Insight and social adequacy were strictly preserved. A general physical exam was unremarkable, but notable for the absence of other neurological signs.

Neuropsychological evaluation evidenced intense visuospatial and visual analytic deficits. She could not perform the Hooper Visual Organization Test or the Colored Progressive Raven Matrices. The visual impairment precluded the evaluation of the other cognitive domains, especially language functions. She was also unable to recognize properly the components of the Biscuits' Theft Figure. Severe difficulty was also seen in the Block Design Test, Trail Making A and Stroop tests. Laboratory blood screening work up for dementia performed accor- ding to international consensus was unremarkable. The MRI showed focal atrophy featured by prominent bilateral parieto-occipital atrophy. The FDG-PET showed prominent bilateral hypometabolism of parietal and occipital regions (Figure 1). The diagnosis of progressive posterior cortical dysfunction syndrome (PPCD) was made based on clinical and imaging grounds.

\section{DISCUSSION}

The patient's visual impairment was initially attributed by her family to being an ophthalmologic problem. The most disabling symptom in our case was visual spatial/visual perceptual deficits and included features of the Balint's syndrome, and visual disorientation, with presenting complaints such as "difficulty climbing stairs," "difficulty finding the handle of a car" or "difficulty following the lines of text while reading." These symptoms may suggest a primarily ophthalmologic disorder and add to the fact that PCA rarely presents with memory complains, this clinical syndrome may not evoke promptly the diagnosis of a dementia disorder, thus postponing its correct treatment. For that reason, it is essential to rule out primary ophthalmologic causes when diagnosing PPCD ${ }^{(6,7)}$. In fact, according to some authors ${ }^{(8)}$, PPCD can sometimes be misattributed to ocular causes, such as cataract or macular disease.


Figure 1. In the left column are brain FDG-PET images of our case. In the middle column are co-registered images with a MRI reference model and statistical SPM diagrams (hypermetabolism in red and hypometabolism in green). In the left column are the Brodmann anatomic division areas. Lines are positioned in three anatomical references: two in Brodmann area 22 (posterior temporal and inferior parietal) and one in right occipital lobe. 
PPCD is capable of damaging both the dorsal (related to spatial analysis) and ventral (related to spatial recognition) visual processing streams, where both deficits can be found in the same patient ${ }^{(7)}$. Both lower and higher level visual impairments contribute to the complex visual symptoms associated with PPCD, as reported by one study ${ }^{(9)}$ that investigated tasks of visual acuity, line orientation, contour integration, and rotated object comparison. PPCD patients had low performance when compared to controls in low level visual functions of visual acuity and line orientation, suggesting that early visual processing areas including $\mathrm{V} 1$ were impaired, as well as higher level visual functions of contour integration, mediated by extrastriatal areas, and the most complex task of object rotation, relying on processing within inferior temporal, parietal, and frontal cortices ${ }^{(9)}$. Visual field defects (VFD) may also be found in PPCD(10). VFD in PPCD are characterized by homonymous visual field defects or bilateral constriction. This observation probably reflects a posterior shift of cortical pathology to the primary and early secondary visual cortices in PPCD(10). VFD testing should be considered in older patients with unexplained visual complaints, particularly when associated with difficulty driving, which may indicate the possibility of PPCD and prompt early neurobehavioral evaluation.

\section{REFERENCES}

1. Benson DF, Davis RJ, Snyder BD. Posterior cortical atrophy. Arch Neurol. 1988;45(7): 789-93

2. Victoroff J, Ross GW, Benson DF, Verity MA, Vinters HV. Posterior cortical atrophy. Neuropathogic correlations. Arch Neurol. 1994;51(3):269-74.

3. Caine D. Posterior cortical atrophy: a review of literature. Neurocase. 2004;10(5):382-5.

4. Tang-Wai DF, Graff-Radford NR, Boeve BF, Dickson DW, Parisi JE, Crook R, et al. Clinical, genetic, and neuropathologic characteristics of posterior cortical atrophy. Neurology. 2004;63(7):1168-74

5. Caixeta L. Huntington's disease presenting as posterior cortical atrophy. Arq Neuropsiquiatr. 2011:69(2B):407-8

6. Areza-Fegyveres R, Caramelli P, Porto CS, Ono CR, Buchpiguel CA, Nitrini R. The syndrome of progressive posterior cortical dysfunction: a multiple case study and review. Dement Neuropsychol. 2007;1(3):311-9.

7. Porto FH, Machado GC, Morillo LS, Brucki SM. Progressive posterior cortical dysfunction. Dement Neuropsychol. 2010;4(1):75-8.

8. Renner JA, Burns JM, Hou CE, McKeel JR. DW, Storandt M, Morris JC. Progressive posterior cortical dysfunction: a clinicopathologic series. Neurology. 2004;63(7): $1175-80$

9. Metzler-Baddeley C, Baddeley RJ, Lovell PG, Laffan A, Jones RW. Visual impairments in dementia with Lewy bodies and posterior cortical atrophy. Neuropsychology. 2010; 24(1):35-48.

10. Pelak VS, Smyth SF, Boyer PJ, Filley CM. Computerized visual field defects in posterior cortical atrophy. Neurology. 2011;77(24):2119-22.

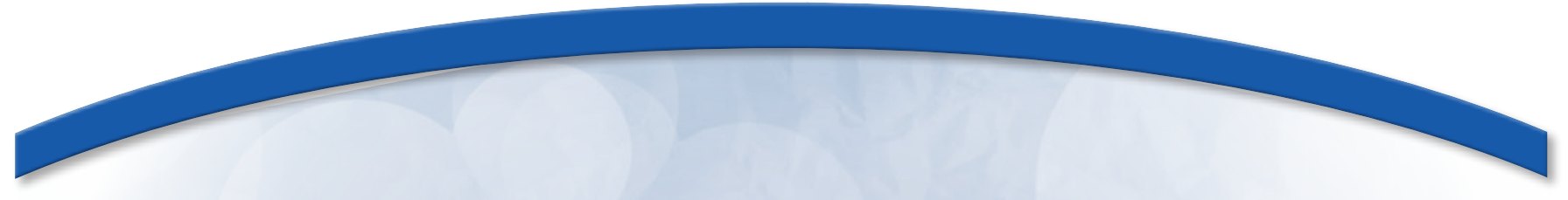

\title{
37ํㅗpósio Internacional Moacyr Ấlvaro - SIMASP
}

\section{3 a 15 de fevereiro de 2014}

\author{
Maksoud Plaza Hotel
}

São Paulo (SP)

\section{Informações:}

Tels.: (11) 5084-4246/5081-7028

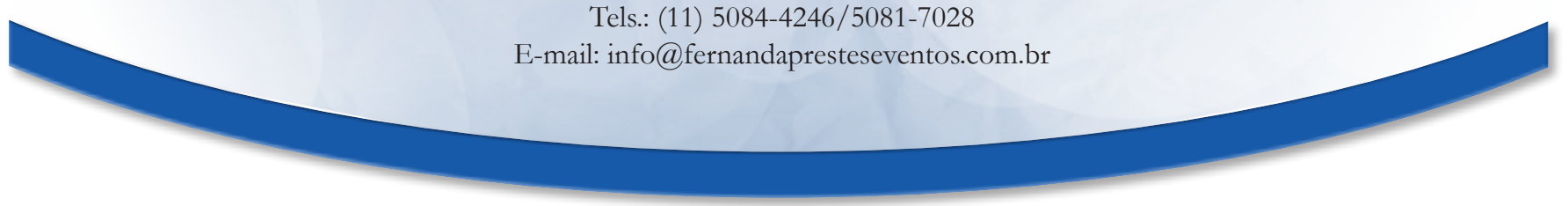

